Resenha do livro:

HOLLOWAY, John. Fissurar o capitalismo. [trad. Daniel Cunha]. São Paulo: Publisher Brasil, 2013.

Por: Lalo Watanabe Minto

\title{
SUPERAR O CAPITALISMO POR MEIO DAS FISSURAS DE JOHN HOLLOWAY
}

Em Fissurar o capitalismo (Crack capitalism, no original em inglês, de 2010), o pensador irlandês, John Holloway ${ }^{1}$, segue uma mesma linha de reflexão apresentada em seu primeiro livro publicado no Brasil, Mudar o mundo sem tomar o poder (2003). Separadas por quase uma década, ambas as obras possuem um mérito inegável: o de ter como horizonte a necessidade de superação do modo de produção capitalista, num contexto em que parte significativa da intelectualidade crítica parece não compartilhar mais de tal horizonte. Quando muito, estes setores reduzem-na a mero expediente intelectual (pior nas vertentes restritas a nichos acadêmicos), como um slogan a ser pronunciado sempre que conveniente.

A principal tese defendida nessa recente obra é tão simples quanto aparentemente impossível: se o mundo que está aí é feito pela atividade humana, muda-lo exige apenas que paremos de fazê-lo do modo atual e que o façamos de outros modos. Não se trata de criar uma nova política ou uma outra economia, mas de combater o antagonismo que está na origem de todos os problemas sociais: a abstração do fazer (doing) em trabalho (labour - trabalho abstrato). No fundo, a provocação é a seguinte: não se pode destruir um sistema como o capitalismo lutando contra o que ele tem de mais sólido (suas estruturas), sendo necessário que o mesmo seja atacado nas suas fragilidades, derrubado pouco a pouco, como o fora na transição do feudalismo para o capitalismo. Nas palavras do autor, como um "processo intersticial" (p. 15).

O antagonismo entre o fazer o trabalho abstrato, com o predomínio deste sobre o primeiro, é um processo vivo e não algo do passado, diz Holloway. Entretanto, não pode ser um domínio total, o que torna esse antagonismo uma "fonte de esperança". Essa apreensão teria sido negligenciada por grande parte da tradição marxista, tal qual um "marxismo de um olho só" (p. 149-150), que teria abandonado a perspectiva do duplo caráter do trabalho. Somos levados, então, à seguinte questão: o capitalismo, enquanto modo de controlar a atividade vital dos homens, pode ser combatido para ser destruído, ou isto nos remete ao campo de suas próprias determinações, aprisionando-nos, de certa forma, ao seu domínio? ${ }^{2}$

O que o autor propõe é que se "fissure" o capitalismo. O combustível do fazer humano que produz essas fissuras, diz ele, não é exatamente a consciência da sua necessidade, mas, antes, a sensibilidade compartilhada por milhões de pessoas em todo o mundo, diuturnamente desafiadas pelas contradições do modo capitalista de viver e produzir a própria existência. A possibilidade de superação do capital não decorreria, portanto, do fato de que a hegemonização do modo de produção capitalista tenha dado origem ao proletariado como classe antagonista. Para Holloway, o antagonismo reside na luta do fazer humano (a dimensão ineliminável do ser social) contra o trabalho abstrato (massa indiferenciada de atividade destinada ao fim de gerar, acumular e reproduzir o valor / capital). Uma luta que não dependeria diretamente das classes. 
Diferentemente do "duplo caráter do trabalho" d'O capital de Marx, Holloway prefere fazer outra distinção: entre doing (e não work) e labour, haja vista que work, ao seu ponto de vista, ainda estaria de certo modo atado à lógica da alienação do trabalho. Para o autor, essa separação é importante para mostrar que somente com o capitalismo o trabalho emergiu como atividade que se destaca da vida em geral, impondo-se ao trabalhador como sofrimento e pesar. E nisto ele é claro: se é o trabalho que produz o capital (p. 104), não se trata de uma luta do trabalho contra o capital (como na "tradição comunista clássica"), mas a fissura "é a revolta do fazer contra o trabalho" (p. 85, grifo nosso).

$\mathrm{O}$ que parece ser inovador também pode se converter, como veremos adiante, em sua principal limitação: sustenta-se que não é o work (trabalho concreto, útil) que deve se sobrepor ao labour (trabalho abstrato, que produz valor de troca), haja vista a necessidade de um novo fazer (doing) não pautado pela lógica do capital, isto é, não referenciado pela relação entre trabalho concreto e trabalho abstrato. Do mesmo modo,

Está claro que o movimento do fazer útil contra o trabalho não pode ser reduzido às lutas relacionadas ao trabalho em nenhum sentido estrito. (HOLLOWAY, 2013, p. 190).

Fissurar o capitalismo defende que não se pode perder de vista que, por mais precárias e desumanizadoras que sejam as condições concretas em que se exerce a atividade produtiva, a possibilidade de construção de uma outra sociedade reside no caráter ineliminável da atividade humana consciente (o fazer): "se nós a produzimos, podemos rompê-la". (p. 95). Noutras palavras, "Se queremos mudar a sociedade, temos que deter a subordinação de nossa atividade ao trabalho abstrato, devemos fazer algo diferente" ( $p$. 130). Até aí as conclusões categóricas de Holloway, revelando também sua simpatia para com o anarquismo, soam como obviedades para um leitor familiarizado com a obra de Marx. Porém, os elementos mais polêmicos da obra emergem dos desdobramentos dessa tese central: "As revoltas minúsculas, subterrâneas, podem ser muito mais radicais em seu potencial do que a mais barulhenta manifestação" (p. 79).

Teríamos aí uma versão requentada de propostas espontaneístas de transformação social? Holloway não demonstra estar preocupado com essa acusação. Igualmente com as críticas, por vezes inevitáveis, que poderiam ser feitas ao caráter romântico que emerge de suas propostas, bem como de seu flerte com o ideário pós-moderno. Nesse sentido, é inegável que a ênfase (um tanto quanto prolixa) no fazer contém uma dimensão aleatória, que postula a possibilidade de construção do novo, sem saber precisamente o que se quer construir e quem pode fazê-lo objetivamente.

Holloway está convicto de que as estratégias convencionais centradas em discursos sobre a necessidade de superação do capital são menos eficazes do que um "fazer ressoar" das inquietações e insatisfações, enfim, o efeito de "contágio" que estas micromanifestações podem produzir. Ou seja, de como podem se tornar fissuras. Mas para viabilizarem-se enquanto tal, precisam estar orientadas para uma luta "contra-e-mais-além do capitalismo", ou seja, não serem reabsorvidas pelo sistema de relações dominantes, que tem no Estado um agente crucial. Neste aspecto, não aponta dúvidas e sim uma certeza: a de que, para superar o capital não se pode fazer uso das mesmas forças que este utiliza para a dominação e para evitar a transformação social. Nas palavras do autor, tem de ser uma luta assimétrica, baseada em novos instrumentos, na criação de algo novo.

Fissurar o capitalismo é o modo como Holloway enxerga uma possibilidade de reencontro entre a vida social e a dimensão humana do fazer, que ficou "nas sombras" com a generalização do trabalho abstrato nas condições desse modo de produção. Daí a 
restrição do autor quanto ao uso do termo "trabalho": "a luta contra o capital é a luta contra aquilo que o produz, é a luta contra o trabalho" (p. 104).

Inegavelmente, um dos méritos de Holloway (a outros poderão ocorrer juízos completamente opostos, certamente) é o de provocar incômodo naqueles que se assentam nas cadeiras cativas de organizações de esquerda e de nichos acadêmicos marxistas, sempre prontos a desqualificar toda e qualquer forma de mobilização social que não seja convencional ou subordinada às suas ortodoxias. Outro mérito decorre da proposta de ler categorias marxianas - como as de trabalho concreto e trabalho abstrato - na realidade histórica, isto é, com base nas experiências concretas desses modos de fazer contra o capital, que abrem possibilidades reais de luta, ao modo como propusera Harry Cleaver em seu Leitura política de O capital, de 1979, aliás, citado na obra.

Já uma das grandes fragilidades decorre da apreensão de que tudo já está acontecendo, bastando que se reconheça como tal. Donde o simplismo recorrente e expresso na afirmação de que "nós mesmos criamos a prisão. Ela é produto do trabalho abstrato" (p. 159), apelando a um "nós" genérico e ocultando o fato de que o trabalho, para ser abstrato, pressupõe que, em relações sociais historicamente determinadas, alguém exerça controle sobre o trabalho/atividade humana alheias. Ou seja, de que alienar o controle do trabalho só é possível quando objetivado em relações concretas, com sujeitos e classes determinadas.

Com efeito, o "grito de revolta" do fazer contra o trabalho abstrato que o autor enxerga em inúmeras formas de manifestação social assume, aqui, a qualidade de expressões do antagonismo que funda a sociedade capitalista. São mais questões do que respostas, completa. O desafio é superar as lutas por sobrevivência, características do trabalho abstrato, sobrepondo-a por uma luta por viver, característica do fazer humano. Onde, então, o autor recorre novamente a uma tese clássica de Marx para afirmar que, já que as forças produtivas (ou "de produção") estão para as relações de produção do mesmo modo que o fazer está para o trabalho abstrato, a saída seria recuperar tais forças para "nós". Mas não propõe modos concretos e objetivos de organizar tal superação, resignando-se a reconhecer e valorizar os 'gritos' contra o trabalho abstrato que, segundo ele, podem ser observados nas mais pequenas ações, conscientes ou não, dos indivíduos e grupos sociais.

Estando certo de que esses gritos precisariam se conectar de forma inovadora, ganhando outra dimensão e outro poder contra a ordem do capital, não há, porém, propostas objetivas. Esse difícil reconhecimento vem do próprio Holloway, quando afirma que, no fundo, "não sabemos como parar de produzir o capitalismo" (p. 245). É preciso reconhecer também que, ao tentar de todos os modos, esvaziar as esferas de organização e luta tradicionais dos trabalhadores contra o capital, sobrevalorizando a esfera da subjetividade na qual uma "vontade" revolucionária poderia superar os mecanismos aprisionadores do capital, o autor tenha se enveredado pelo caminho da inviabilização de qualquer tipo de luta. Afinal, algo essencial está ausente: nesse novo mundo construído a partir de um fazer orientado pela necessidade e pelo desejo das pessoas, não pelo "trabalho", quem é que produzirá - e de que maneira - as condições materiais da vida humana?

Está claro que o autor não entende suas propostas como prontas e acabadas, mas como um processo a construir, um fazer humano para a transformação radical da sociedade e desse próprio fazer, expresso na afirmação de que a "revolução não é a destruição do capitalismo, mas a recusa de criá-lo" (p. 244). Não podemos nos esquecer, porém, que recusar certa forma de produzir e reproduzir o fazer humano não implica um não fazer pleno. Isto é, a produção das condições de existência é conditio sine qua non da vida 
social. Terá Holloway se esquecido desse elemento tão essencial e acreditado que é possível uma "recusa" do trabalho sem que se coloque algo em seu lugar, isto é, que seria ela própria (a recusa) esse novo fazer humano, emancipador? ${ }^{3}$

Raciocinando nesses termos, Fissurar o capitalismo pode conter, no limite, a sugestão de uma vida ascética como meio para a superação do "trabalho", o que nada tem de revolucionário, mas sim de retrógrado e conservador. Ou, ainda, da postulação de um auto-desalienar-se do trabalho, negando a própria auto-alienação. Pura epifania. O fato é que a ênfase em promover a todo custo um fazer desalienado do trabalho humano em geral, revela antes as simpatias do autor pelo anarquismo do que pelo marxismo. E expressa a dificuldade contemporânea de tratar do problema do sujeito revolucionário.

Resta considerar que se o tema é demasiado polêmico, de modo algum é irrelevante. A não pretensão do autor em apresentar verdades dadas e acabadas, pode ajudar a abrir a cabeça de seus leitores, alertando-os para as inúmeras questões que se põem na ordem do dia. E o mais importante: a perspectiva de superação do capitalismo, reafirmada a todo instante, não se apresenta aqui como mero slogan. Por um lado, porque leva em conta as experiências concretas do século $\mathrm{XX}$, às quais o autor é crítico, e, por outro lado, pois refuta as idealizações de uma "revolução" que vá simplesmente instaurar uma sociedade comunista. As questões concretas da revolução no século XXI são desafios postos para todos os marxistas e Holloway se propõe a enfrenta-las. Que bom aprendizado possa ser tirado da leitura.

\footnotetext{
${ }^{1}$ John Patrick Holloway Kennedy é licenciado em Línguas Modernas e Direito, pela Universidade de Cambridge e Doutor em Ciência Política, pela Universidade de Edimburgo. Disponível em: <http://148.228.173.140/icsyhweb/sociologia.html>. Acesso em: 01 jun. 2015.

${ }^{2}$ Essa crítica está diretamente vinculada às propostas do autor em "Mudar o mundo sem tomar o poder". Para duas leituras críticas, bastante distintas, dessa obra, ver Ivo Tonet (Disponível em:

http://ivotonet.xpg.uol.com.br/arquivos/Sobre_MUDAR_O_MUNDO_SEM_TOMAR_O_PODER_de_John _Holloway.pdf>, Consulta em: 27 maio 2015) e Michael Löwy (disponível em:

<http://www.ifch.unicamp.br/criticamarxista/arquivos_biblioteca/resenha90critica20-R-lowy.pdf〉, consultado em 28 maio 2015).

3 “Com a nossa capacidade social de prover as necessidades básicas da vida (com o desenvolvimento atual das forças produtivas, para usar uma linguagem mais tradicional), não há razão para não sermos capazes de viver bastante satisfeitos com um tecido social de muitos pedaços dispersos e muitas pontas soltas, atividades heterogêneas que não levam de nenhuma maneira óbvia a um benefício social reconhecível, ou numa situação em que o único benefício social direto é a liberdade de fazer a sua própria coisa”. (Holloway, 2013, p. 213). Neste trecho o autor parece se aproximar de uma concepção neutra de força produtiva, o que ajuda a explicar a facilidade com a qual eleva manifestações espontâneas à condição de "fissuras", isto é, de potenciais mecanismos de revolução da sociedade capitalista, sem ter que recorrer a algo que se coloque em seu lugar, sobretudo para resolver a questão incontornável da produção material da vida.
} 